\title{
Introduction to the special issue on ownership, control and regulation
}

\author{
Mark Bagnoli · Susan Watts
}

Published online: 7 August 2011

(C) Springer-Verlag 2011

Different ownership structures and the separation of ownership and control interact with changes in the regulatory environment to affect firm performance, financial disclosures and contracts and compensation. The purpose of this symposium is to present a set of papers that provide insight into the effects of these interactions and their effects in a variety of settings.

Three of our papers study the impact of corporate governance on firm performance and contracting with a particular focus on how firms in different countries mitigate agency problems that arise in corporations. Santiago-Castro and Brown (2011) identify distinctive characteristics of Latin American markets (e.g., a relatively weak legal environment coupled with poor market corporate governance mechanisms and the pervasiveness of family-controlled firms) that exacerbate the conflict of interest between majority and minority shareholders. SB show that the severity of this conflict is related to board of director structure, family control and CEO shareholdings. Interestingly, company affiliation with a grupo (a term used in Latin America for a form of business in which shareholders have control rights in excess of the cash flows rights) reduces minority shareholder expropriation.

The second paper in this set (Praet 2011) studies Belgian firms with highly concentrated ownership. Again, focusing on the agency problem that arises when a controlling shareholder has the ability to extract benefits at the expense of minority shareholders, Praet examines whether the decision by a company to divest assets is driven by this motive. Praet finds that poorly performing subsidiaries are more likely to lead to

\footnotetext{
M. Bagnoli ( $\varangle) \cdot$ S. Watts

Krannert Graduate School of Management, Purdue University, 100 S. Grant Street, West Lafayette, IN, 47907-2076, USA

e-mail: mbagnoli@purdue.edu

S. Watts

e-mail: swatts@purdue.edu
} 
divestiture, but that the degree of ownership concentration determines, at least in part, whether agency motives or efficient monitoring drive the decision.

The third paper in this set (Bagnoli et al. 2011) studies family controlled firms in the U.S. with a special focus on debt contracting. BLS argue that the close alignment of management's and shareholders' interests in family firms exacerbates the debtholder-shareholder conflict, particularly if a family member is a CEO or if family control is increased with the use of dual-class shares. They hypothesize and provide evidence that family firms in the U.S. more frequently have covenants that restrict the firm's ability to divert cash and/or assets to the shareholders at the expense of the debtholders in their private lending agreements.

The two remaining papers in the issue study the impact of regulation on the information produced by corporations and analysts. The first of these two papers (Arya and Mittendorf 2011) focuses on the progressive tax code and how it influences corporate disclosure policy. Prior research shows that competitive concerns help to shape corporate disclosure policy. However, while disclosure policies are often motivated by a desire for a large payoff, a progressive tax system can reduce those payoffs by inducing risk-aversion and a preference for a smooth income stream. AM argue that this can lead to efficient information sharing and may provide benefits beyond those of a policy of mandatory full disclosure.

The second of this last set of papers (Clarke et al. 2011) examine the effect of stock exchange rules (NASD Rule 2711 and NYSE Rule 427, both adopted in 2002) and the so-called Global Research Settlement of 2003 on the stock recommendations issued by independent, affiliated and unaffiliated equity analysts. These rules were designed to mitigate the potential conflicts of interest of security analysts that became apparent after the dot.com boom of the late 1990s. Collectively, the new regulations severely limited communication between investment bankers and personnel in the research departments of the same firm, prohibited the tying of analyst compensation to investment banking business and banned corporations from reviewing (offering guidance on) analyst research before it is published. CKPR show that effects of the new regulations did not necessarily result in higher quality research for the investing public. Specifically, following adoption of these regulations, analysts affiliated with investment banks were in fact less likely to issue strong buy recommendations; however, their more prevalent downgrades became less informative to the stock market. Independent analysts were more likely to issue buy recommendations in the same period, but the more optimistic recommendations issued by analysts at independent firms set up after the regulations took effect generated lower announcement period returns. Unaffiliated analysts were more likely to issue recommendations that were supported by concurrent earnings forecasts in the same period.

Collectively, these papers demonstrate the importance of firm structure, local corporate governance and regulation on the information that is available to investors, creditors and information intermediaries and highlights the importance of understanding how these relations vary across cultures and countries. 


\section{References}

Arya, A., Mittendorf, B.: The interaction between corporate tax structure and disclosure policy. Ann Finance 7 (2011, in this issue). doi:10.1007/s10436-009-0123-0

Bagnoli, M., Liu, H., Watts, S.: Family firms, debtholder-shareholder agency costs and the use of covenants in private debt. Ann Finance 7 (2011, in this issue). doi:10.1007/s10436-009-0127-9

Clarke, J., Khorana, A., Patel, A., Rau, R.: Independents' Day? Analyst behavior surrounding the Global Settlement. Ann Finance 7 (2011, in this issue). doi:10.1007/s10436-009-0136-8

Praet, A.: Voluntary firm restructuring: why do firms sell or liquidate their subsidiaries? Ann Finance 7 (2011, in this issue). doi:10.1007/s10436-010-0154-6

Santiago-Castro, M., Brown, C.: Corporate governance, expropriation of minority shareholders' rights, and performance in Latin America enterprises. Ann Finance 7 (2011, in this issue). doi:10.1007/ s10436-009-0132-z 